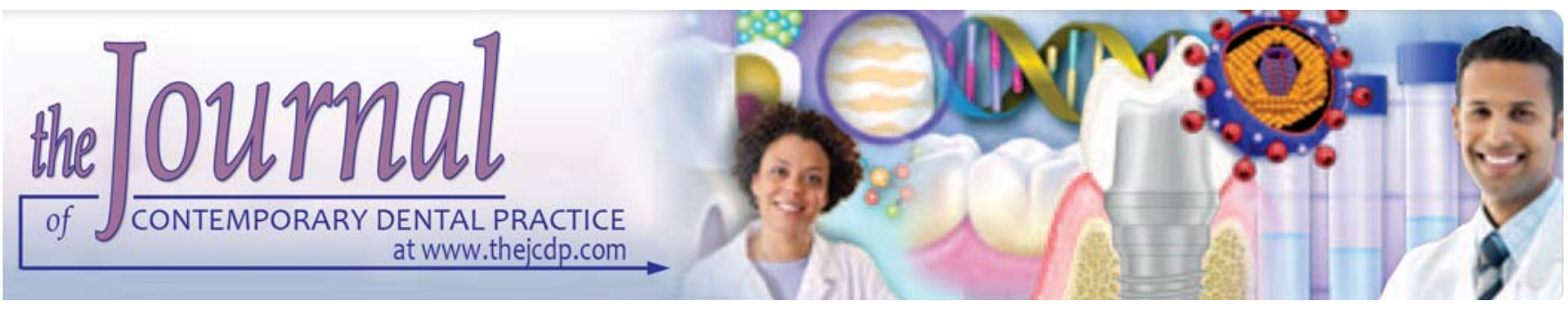

\title{
Association of Temporomandibular Joint Dysfunction, Condylar Position and Dental Malocclusions in Davangere Population
}

\author{
Malthesh B Savakkanavar, S Sridhar, D Dinesh, KS Girish, GC Ramesh
}

\section{ABSTRACT}

Aims:

- To study the association between dental malocclusions and temporomandibular joint dysfunction.

- To study the association between dental malocclusions and condylar position.

- To study the association between temporomandibular (TM) joint dysfunction and condylar position.

Methods: The subjects were divided into four groups for dental malocclusions viz. class I malocclusion with or without TM dysfunction, class II division 1 malocclusion with or without TM dysfunction, class II division 2 malocclusion with or without TM dysfunction and class III malocclusion with or without TM dysfunction. Once the patient fulfilled the criteria, the presence or absence of signs of TM dysfunction were elicited from the patient.

Results: It shows the association between TM dysfunction signs and left and right condylar positions. It shows the association between TM dysfunction symptom and left and right condylar positions. It shows the association between dental malocclusions and TM dysfunction signs and symptom. It shows the association between dental malocclusions and left and right condylar positions.

Conclusion: There was an association between TM dysfunction signs and left and right condylar positions. But, there was no association between TM dysfunction symptoms and left and right condylar positions. There was an association between dental malocclusions and TM dysfunction signs. But there was no association between dental malocclusions and TM dysfunction symptoms. There was an association between dental malocclusions and left condylar position, but there was no association between dental malocclusion and right condylar position.

Clinical significance: This study indicates that malocclusions and factors of condylar position should be seen as merely cofactors in the sense of one piece of the mosaic in the multifactorial problem of TM dysfunction. TM dysfunction factors that showed significant effects to various malocclusions through this study. This study shows clinical significance of association of various types of dental malocclusions to different conylar positions and TM dysfunction signs and symptoms. Before treating orthodontic patients, one should evaluate and treat the TM disorders for better prognosis.

Keywords: Temporomandibular joint dysfunction, Condylar position, Dental malocclusions, Transcranial radiograph, Lateral cephalogram.

How to cite this article: Malthesh B Savakkanavar, Sridhar S, Dinesh D, Girish KS, Ramesh GC. Association of Temporomandibular J oint Dysfunction, Condylar Position and Dental Malocclusions in Davangere Population. J Contemp Dent P ract 2012;13(4):528-533.

\section{Source of support: Nil}

Conflict of interest: None declared

\section{INTRODUCTION}

Orthodontists are constantly being challenged with the task of providing their patients with acceptable esthetics and masticatory function. Therefore, the orthodontist must always consider the ways in which orthodontic therapy affects function. To maximize sound orthopedic function, the occlusal condition must be finalized in harmony with the stable position of the temporomandibular (TM ) joints and any orthopedic instability relates to TM disorders. The malocclusion may be relevant to inducing functional imbalance of the musculature and malposition of the condyle in the TM joint, which are further related to the occurrence of T M disorders. ${ }^{1} \mathrm{~B}$ oth functional and morphologic aspects of the occlusion have been implicated as causative factors. ${ }^{2}$

TM dysfunction is a generic term for a number of clinical signs and symptoms involving the masticatory muscles, the TM joints and associated structures. ${ }^{3}$ F unctional disturbances of the masticatory system in children and adolescents are common and seem to increase with age into adulthood. ${ }^{3}$ Although the cause of TM dysfunction is obviously multifactorial, malocclusion is considered to be one of the 
Association of Temporomandibular J oint Dysfunction, Condylar Position and Dental Malocclusions in Davangere Population

contributing factors. Eccentric position of the condyle in the glenoid fossa may cause TM joint pain and TM dysfunction. ${ }^{4}$ The position of the mandibular condyles in the glenoid fossa is an important factor in treatment planning for TM joint disorders. ${ }^{5}$ As there are only few studies in this field especially among our Indian population, this study has been undertaken to determine the association between TM dysfunction, condylar position and dental malocclusions in Davangere population, which is a place situated in K arnataka, in the Southern part of India.

\section{AIMS AND OBJECTIVES}

1. To study the association between dental malocclusions and TM joint dysfunction.

2. To study the association between dental malocclusions and condylar position.

3. To study the association between TM joint dysfunction and condylar position.

\section{METHODOLOGY}

\section{Source of Data}

The present study evaluated 80 subjects having dental malocclusions from the Department of Orthodontics, College of Dental Sciences and Davangere.

The subjects were divided into four groups for dental malocclusions, viz class I malocclusion (Fig. 1) with or without TM dysfunction, class II division 1 malocclusion with or without TM dysfunction, class II division 2 malocclusion with or without TM dysfunction and class III malocclusion with or without TM dysfunction.

\section{Criteria for Patient Selection}

1. Patients having dental class I, class II division 1, class II division 2 and class III malocclusions with or without TM dysfunction.

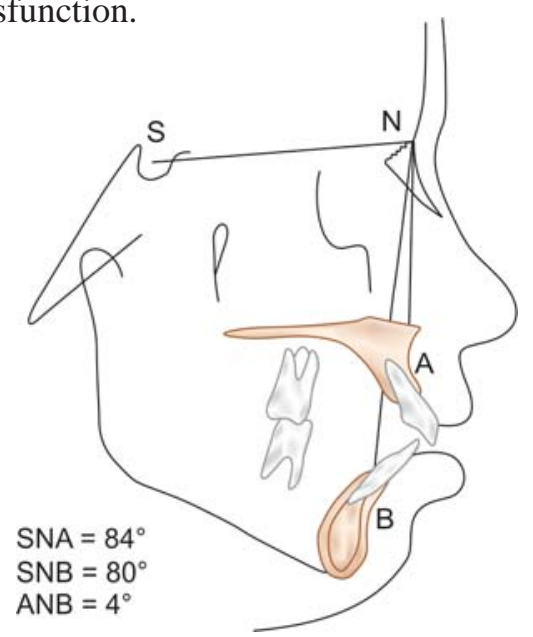

Fig. 1: Lateral cephalogram showing class I malocclusion (case 1)
2. Patients should be aged between 15 and 25 years.

3. Patients must belong to local Davangere population.

\section{List of Armamentarium}

1. Instruments used for screening: M outh, mirror, explorer, straight, probe, tweezer, kidney, tray, gloves, mouth mask.

2. Instruments used for tracing radiographs. Transparent cellul ose acetate sheet, light box, lead pencil, measuring scale-protractor, eraser.

3. Radiographic equipment: Advanced panoramic and cephalometric equipment.

4. Radiographic films: Standard $8 \times 10$ " K odak T-mat TM E gold, lateral radiographic head film, standard $6 \times 12$ " K odak T-mat TM E gold, transcranial radiographic head film.

\section{Methods}

By considering the above-mentioned inclusion criteria, the subjects were selected for our study. Once the patient fulfilled the criteria, the presence or absence of signs of TM dysfunction were elicited from the patient.

The clinical signs of TM dysfunction were scored as follows:

1. Maximal mouth opening $(0 \geq 40 \mathrm{~mm}, 1=30$ to $39 \mathrm{~mm}$, $2 \leq 30 \mathrm{~mm}$ ).

2. M andibular deflection during opening movement $(0 \leq$ $2 \mathrm{~mm}, 1=2$ to $5 \mathrm{~mm}, 2 \geq 5 \mathrm{~mm}$ ).

3. Impaired TM joint function [(clicking, locking, luxation); ( $0=$ no impairment, 1 = palpable clicking, 2 = evidently clicking, locking, luxation)].

4. TM joint pain ( $0=$ no pain, $1=$ pal pable pain, $2=$ palpebral reflex).

5. M uscle pain ( $0=$ no pain, $1=$ pal pable pain, $2=$ pal pebral reflex).

The sum of the scores (points) form the basis of grouping by grade of dysfunction, where $0=$ no dysfunction, $I=$ mild dysfunction (1-4 points), II = moderate dysfunction (5-9 points), III = severe dysfunction ( $>9$ points).

The patient was asked for the presence or absence of symptom of TM dysfunction, i.e. headache.

A lateral cephalogram and a transcranial radiograph ${ }^{9}$ of each patient were taken in the department of oral medicine and radiology.

\section{PROFORMA}

\section{Signs and Symptom ${ }^{11}$ of TM Dysfunction}

1. Maximal mouth opening: $(0 \geq 40 \mathrm{~mm}, 1=30$ to $39 \mathrm{~mm}$, $2 \leq 30 \mathrm{~mm}$ ). 
2. M andibular deflection during opening movement: $(0 \leq$ $2 \mathrm{~mm}, 1=2$ to $5 \mathrm{~mm}, 2 \geq 5 \mathrm{~mm}$ ).

3. Impaired TM J oint function (clicking, locking, luxation): ( 0 = no impairment, $1=$ pal pable clicking, $2=$ evident clicking, locking, luxation).

4. TM Joint pain: $(0=$ no pain, $1=$ palpable pain, $2=$ palpebral reflex).

5. M uscle pain: $(0=$ no pain, $1=$ palpable pain, $2=$ pal pebral reflex).

\section{Grades of TM Dysfunction}

$0=$ no dysfunction, $1=$ mild dysfunction (1-4 points), 2 = moderate dysfunction (5-9 points), $3=$ severe dysfunction (>9 points)

\section{Types of Malocclusion}

Dental malocclusions: Class I/class II div1/class II div 2/ class III.

\section{Position of Condyle}

- Left condyle: A nterior/concentric/posterior

- Right condyle: Anterior/concentric/posterior.

\section{STATISTICAL ANALYSIS}

Descriptive data are present as number and percentages for each of the categories. Chi-square test was used to find any significant difference between the groups. A p-value of less than 0.05 was considered for statistical significance.

\section{RESULTS}

The present study was conducted to know the association between TM dysfunction, condylar position and dental malocclusions. A mong 80 patients, who visited the department of orthodontics and dentofacial orthopedics.

\section{DISCUSSION}

The present study was undertaken to determine the association between TM dysfunction, condylar position and malocclusions among Davangere population in Karnataka, a state situated in the southern part of India. In addition to this, the relationship that these parameters share to each other is not known, especially among Indian population.

The age group selected for our study was 15 to 25 years. Since 11 to 15 years is a relatively 'calm' period for reported symptoms of TM dysfunction. A ccording to Riolo M L et al ${ }^{6}$ as age advances the signs and symptoms of TM dysfunction aggravate progressively.

The different malocclusions were evaluated using lateral cephalometric radiograph and the condylar position in the glenoid fossa was ${ }^{12}$ determined using transcranial radiographs. The signs of TM dysfunction have been graded as $0,1,2$ and 3 according to the criteria used by Thilander $B$ et al. ${ }^{3}$

Considering the association between TM dysfunction signs and the left (Graph 1) and right condylar position, we found a statistically significant association between both of them. When the condyle was concentrically placed (Fig. 2), the signs of TM dysfunction were more. A ccording to W einberg $L A^{7}$, condylar displacement also contributes to TM joint dysfunction-pain, depending on its direction.

As for the relationship between the TM dysfunction symptom and the position of the left and right condyle were evaluated, we did not find any statistically significant association between them. A mong 80 patients, the absence of TM dysfunction symptom was seen in 75 patients. Hence, the majority of the patients were symptomless.

When the association betw een dental malocclusions and TM dysfunction ${ }^{13}$ signs (Graph 2) and symptom were considered, we found a statistically significant correlation to exist between the TM dysfunction signs and dental

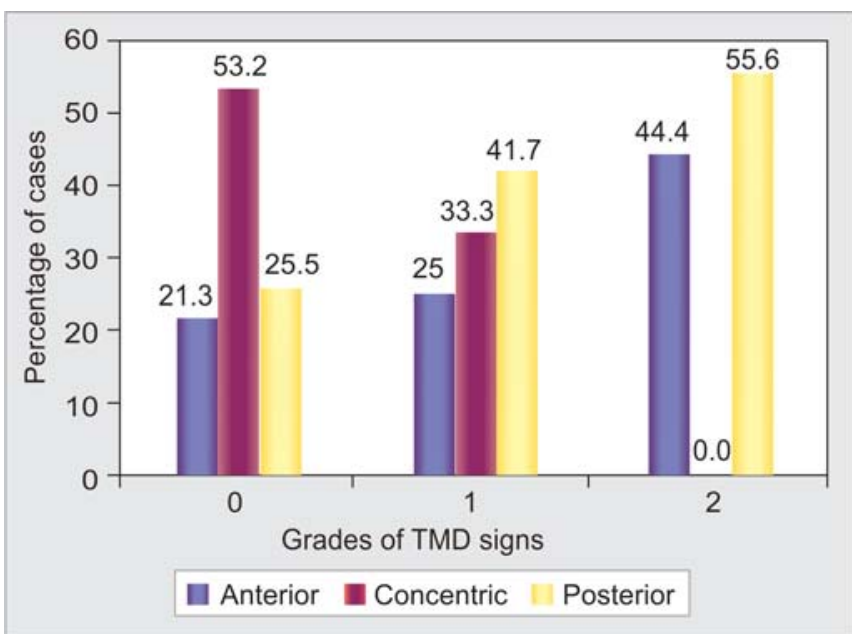

Graph 1: TMD signs in relation to left condylar position

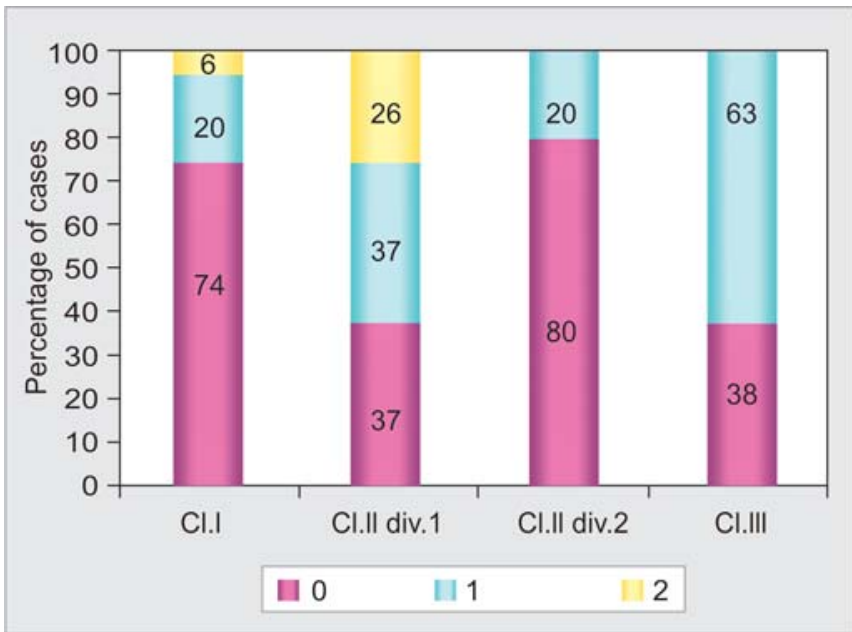

Graph 2: Dental malocclusions in relation to TMD signs 


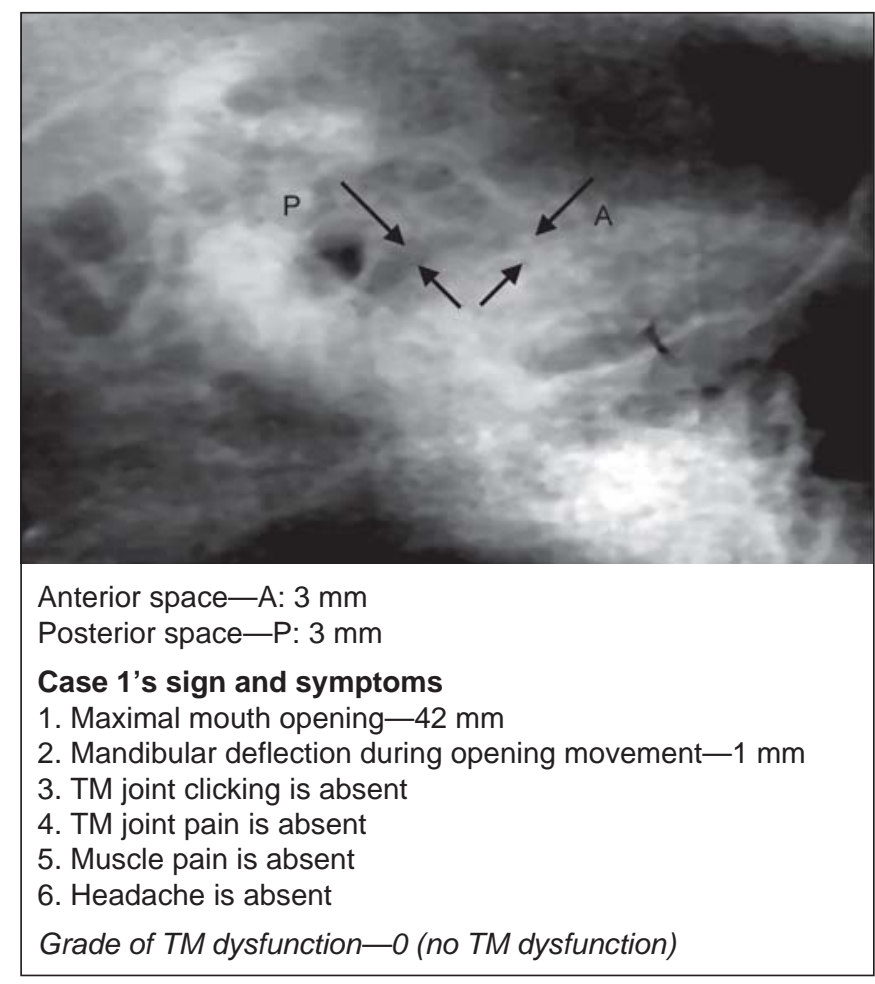

Fig. 2: Transcranial view of case 1 showing concentrically placed condyle

malocclusion, but this relationship could not be established between the TM dysfunction symptom and dental malocclusion.

We attributed this to the fact that the number of patients with TM dysfunction symptoms were very minimal ${ }^{5}$ among 80 patients. The association between TM dysfunction signs and dental malocclusion are in accordance to the previous study by Thilander B et al, ${ }^{3}$ and M ohlin B et al, ${ }^{8}$ wherein they also found a similar correlation to exist between them.

A ccording to our observations of the association between dental malocclusions and the left (Graph 3 ) and right condylar positions, we found a statistically significant association to exist between the presence of dental malocclusions and the left condylar position, which was concentrically placed in comparatively more number of cases (33 out of 80 patients). A similar correlation was not observed between the right condylar position and the dental

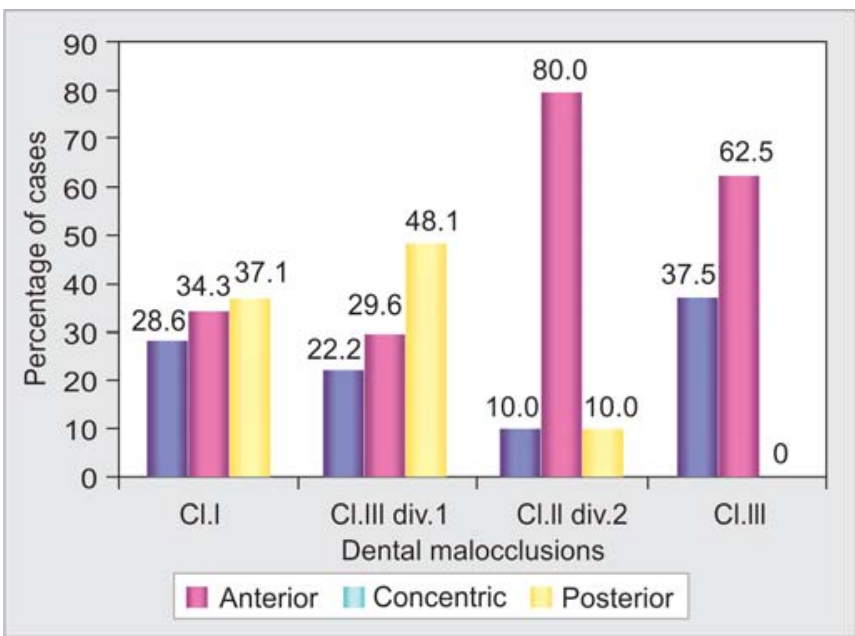

Graph 3: Dental malocclusions in relation to left condylar position

malocclusions, as their association was found to be statistically nonsignificant.

Further research needs to be done, on similar lines, using probably a larger sample size, so that a more definite causative reason for TM dysfunction can be established.

\section{SUMMARY AND CONCLUSION}

This study was conducted to investigate the association between dental malocclusions and TM dysfunction; dental malocclusions and condylar position and TM dysfunction and condylar position.

Eighty subjects between 15 and 25 years of age visiting Department of Orthodontics, College of Dental Sciences Davangere, having dental malocclusions with or without TM dysfunction ${ }^{14,15}$ were selected for the study. Lateral cephalograms were taken, TM dysfunction was evaluated by history and clinical signs and symptoms, and condylar position was estimated from transcranial view radiographs.

Following conclusions were made from the present study:

1. There was an association between TM dysfunction signs and left and right condylar positions (Table 1). B ut, there was no association between TM dysfunction symptoms and left and right condylar positions.

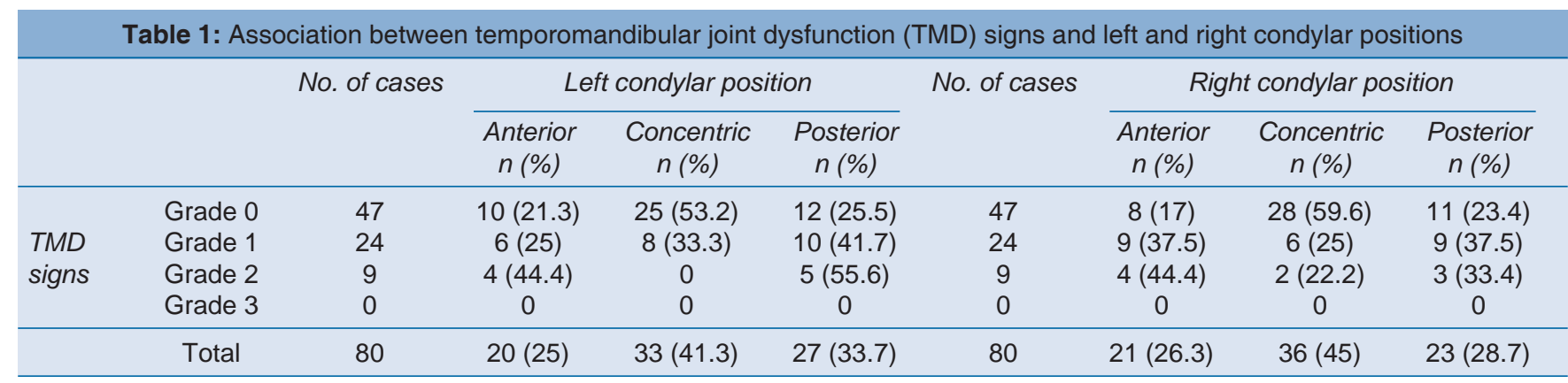

$\chi^{2}: 6.85 ; p<0.05(S) ; \chi^{2}: 10.21 ; p<0.01$ (S) 


\begin{tabular}{|c|c|c|c|c|c|c|c|}
\hline \multirow{2}{*}{$\begin{array}{l}\text { Dental } \\
\text { malocclusions }\end{array}$} & \multirow{2}{*}{$\begin{array}{l}\text { No. of } \\
\text { cases }\end{array}$} & \multicolumn{2}{|c|}{ TMD symptom } & \multicolumn{4}{|c|}{ TMD signs } \\
\hline & & $\begin{array}{l}\text { Headache } \\
\text { present } \mathrm{n}(\%)\end{array}$ & $\begin{array}{c}\text { Headache } \\
\text { absent } \mathrm{n}(\%)\end{array}$ & Grade 0 & Grade 1 & Grade 2 & Grade 3 \\
\hline Class I & 35 & $1(2.9)$ & $34(97.1)$ & $26(74.3)$ & $7(20)$ & $2(5.7)$ & 0 \\
\hline Class II div.1 & 27 & $4(14.8)$ & $23(85.2)$ & $10(37)$ & $10(37)$ & $7(26)$ & 0 \\
\hline Class II div.2 & 10 & 0 & $10(100)$ & $8(80)$ & $2(20)$ & 0 & 0 \\
\hline Class III & 8 & 0 & $8(100)$ & $3(375)$ & $5(62.5)$ & 0 & 0 \\
\hline Total & 80 & $5(6.3)$ & 75 (93.7) & $47(58.8)$ & $24(30)$ & $9(11.2)$ & 0 \\
\hline
\end{tabular}

$\chi^{2}: 2.53 ; p=0.28$ (NS); $\chi^{2}: 12.1, p<0.01$ (S)

Table 3: Association between dental malocclusions and left and right condylar positions

\begin{tabular}{|c|c|c|c|c|c|c|c|}
\hline \multirow{2}{*}{$\begin{array}{l}\text { Dental } \\
\text { malocclusions }\end{array}$} & \multirow[t]{2}{*}{ No. of cases } & \multicolumn{3}{|c|}{ Left condylar position } & \multicolumn{3}{|c|}{ Right condylar position } \\
\hline & & $\begin{array}{c}\text { Anterior } \\
\mathrm{n}(\%)\end{array}$ & $\begin{array}{c}\text { Concentric } \\
\mathrm{n}(\%)\end{array}$ & $\begin{array}{c}\text { Posterior } \\
\mathrm{n}(\%)\end{array}$ & $\begin{array}{c}\text { Anterior } \\
\mathrm{n}(\%)\end{array}$ & $\begin{array}{c}\text { Concentric } \\
\mathrm{n}(\%)\end{array}$ & $\begin{array}{c}\text { Posterior } \\
\mathrm{n}(\%)\end{array}$ \\
\hline $\mathrm{Cl} . \mathrm{I}$ & 35 & $10(28.6)$ & $12(34.3)$ & $13(37.1)$ & $9(25.8)$ & $13(37.1)$ & $13(37.1)$ \\
\hline Cl II div.1 & 27 & $6(22.2)$ & $8(29.6)$ & $13(48.1)$ & $5(18.5)$ & 14 (51.9) & $8(29.6)$ \\
\hline ClII div.2 & 10 & $1(10)$ & $8(80)$ & $1(10)$ & $2(20)$ & $7(70)$ & $1(10)$ \\
\hline $\mathrm{ClIII}$ & 8 & $3(37.5)$ & $5(62.5)$ & 0 & $5(62.5)$ & $2(25)$ & $1(12.5)$ \\
\hline Total & 80 & $20(25)$ & $33(41.3)$ & $27(33.7)$ & $21(26.3)$ & $36(45)$ & $23(28.7)$ \\
\hline
\end{tabular}

$\chi^{2}: 13.6 ; p: 0.03(S) ; \chi^{2}: 10.4 ; p: 0.11$ (NS)

2. There was an association between dental malocclusions and TM dysfunction signs. But, there was no association between dental malocclusions and TM dysfunction symptoms (Table 2).

3. There was an association between dental malocclusions and left condylar position, but there was no association between dental malocclusion and right condylar position (Table 3).

\section{REFERENCES}

1. Tanne K, Tanaka E, Sakuda M. A ssociation between malocclusion and temporomandibular disorders in orthodontic patients before treatment. J Orofacial Pain 1993;7:156-62.

2. Runge ME, Sadowsky C, Sakols EI, BeGole EA. The relationship between temporomandibular joint sounds and malocclusion. A m J Orthod Dentofac Orthop 1989;96:36-42.

3. Thilander B, Rubio G, Pena L, M ayorga CD. Prevalence of temporomandibular dysfunction and its association with malocclusion in children and adolescents. An epidemiologic study related to specified stages of dental development. A ngle Orthod 2002;72:146-54

4. A rtun J, Hollender LG, Truelove EL. Relationship between orthodontic treatment, condylar position and internal derangement in the temporomandibular joint. A m J Orthod Dentofac Orthop 1992;101:48-53.

5. A quilino SA, M atteson SR, H olland GA, Phillips C. Evaluation of condylar position from temporomandibular joint radiographs. J Prothet Dent 1985;53:88-97.

6. Riolo ML, B randt D, Tenhave TR. A ssociations between occlusal characteristics and signs and symptoms of TM J dysfunction in children and young adults. A m J Orthod Dentofac Orthop 1987;92:467-77.
7. Weinberg $L A$. The role of stress, occlusion, and condyle position in TMJ dysfunction pain. J Prosthet D ent 1983;49:532-45.

8. Mohlin B, Ingervall B, Thilander B. Relation between malocclusion and mandibular dysfunction in Swedish men. European J ournal of Orthodontics 1980;229-38.

9. Brooks SL, Brand JW , Gibbs S J , H ollender L, L urie A G, O mnell $K A$, et al. Imaging of the temporomandibular joint. Oral Surg Oral M ed Oral Pathol Oral Radiol 1997;83:609-18.

10. Henrikson $\mathrm{T}, \mathrm{N}$ ilner $\mathrm{M}, \mathrm{K}$ urol J. Signs of temporomandibular disorders in girls receiving orthodontic treatment. A prospective and longitudinal comparison with untreated class II malocclusions and normal occlusion subjects. Eur J Orthod 2000;22:271-87.

11. Egermark I, Carlsson GE, M agnusson T. A 20-year longitudinal study of subjective symptoms of temporomandibular disorders from childhood to adulthood. A cta O dontol Scand 2001;59:40-48.

12. Tsuruta A, Y amada K, Hanada K, Hosogai A, K ohno S, K oyama JI, Hayashi T. The relationship between morphological changes of the condyle and condylar position in the glenoid fossa. J Orofac Pain 2004;18:148-55.

13. Gesch D, B ernhardt $O$, Kocher $T$, J ohn U, Hensel E, A Ite D. A ssociation of malocclusion and functional occlusion with signs of temporomandibular disorders in adults: Results of the population-based study of health in Pomerania. Angle Orthod 2004 A ug;74(4):512-20.

14. M ohlin BO, Derweduwen K, Pilley R, Kingdon A, Shaw WC, Kenealy $P$. M alocclusion and temporomandibular disorder: $A$ comparison of adolescents with moderate to severe dysfunction with those without signs and symptoms of temporomandibular disorder and their further development to 30 years of age. A ngle Orthod 2004 J un; 74(3):319-27.

15. K aselo E, J agomägi T, V oog U. M alocclusion and the need for orthodontic treatment in patients with temporomandibular dysfunction. Stomatologija 2007;9(3):79-85. 


\section{ABOUT THE AUTHORS}

\section{Malthesh B Savakkanavar (Corresponding Author)}

Reader, Department of Orthodontics, Sharavathi Dental College and Hospital, Alkola, Shimoga, Karnataka, India, e-mail: drmaltheshortho@yahoo.com

\section{S Sridhar}

Reader, Department of Orthodontics, SJ M Dental College and Hospital, Chitradurga, K arnataka, India

\section{Dinesh}

Professor and Head, D epartment of Orthodontics, SJM Dental College and Hospital, Chitradurga, K arnataka, India

\section{KS Girish}

Professor and Head, Department of Orthodontics, Sharavathi Dental College and Hospital, Shimoga, K arnataka, India

\section{GC Ramesh}

Assistant Professor, Department of Orthodontics, Sharavathi Dental College and Hospital, Shimoga, K arnataka, India 